\title{
Eosinophilic meningitis due to
}

\section{Angiostrongylus cantonensis with confirmed finding of intrathecal parasite}

\author{
Meningite eosinofílica por Angiostrongylus cantonensis com confirmação intratecal do \\ parasita
}

Sir, the eosinophilic meningitis is an important group of reactive meningitis due to parasite. Of several parasites, Angiostrongylus cantonensis is a round worm that can induce this neurological disorder. The infective parasite larva can be seen in snail and the ingestion of infected snail can result in infestation. This disease can be seen in many tropical countries $^{1,2}$. In Thailand, there are around 1,000 case reports of eospinophilic meningitis and it is usually assumed that the cause of disease is due to Angiostrongylus cantonensis infestation. It should be noted that almost all cases are presumptive diagnosed to have parasitic infestation. Only a few cases with confirmed finding of intrathecal parasite can be seen. Here, the authors try to summarize the evidences of eosinophilic meningitis due to Angiostrongylus cantonensis with confirmed finding of intrathecal parasite in Thailand. The literature search based on PubMed, SCOPUS and ThaiIndexMedicus was performed and there are only 2 reports on 2 cases $^{3,4}$. The first case is a 29 years old male presenting with headache and the second case is a female infant ( 8 months old) presenting with prolonged (2 week period) fever and seizure. The cerebrospinal fluid analyses in both cases match with the eosinophilic meningitis. The number of identified worm in the cerebrospinal fluid of the first and second case is equal to 12 and 11 worms, respectively. The history of snail intake can be seen only in the first case. The second case get no specific antiparasitic drug and the spontaneous recovery can be observed. Based on this information, it can be seen that lower than $1 \%$ of all eosinophilic meningitis cases in Thailand have the confirmative finding of intrathecal Angiostrongylus cantonensis. Most cases are presumptively diagnosed due to clinical history of headache and intake of snail ${ }^{5}$. Although some new diagnostic tools such as antigenic test have been recently introduced the false positive can still be expected and this cannot be the definitive diagnosis as detection of parasite ${ }^{6}$. Based on the present data, there are many interesting information: a) the infection can be seen in infant (and the chief compliant of headache cannot be observed); b) the infection can be spontaneously resolved; c) the history of snail intake might not be available.

Wiwanitkit Somsri ${ }^{1}$, Wiwanitkit Viroj $^{2}$

\section{References}

\footnotetext{
1. Wang $Q P$, Lai $D H$, Zhu $X Q$, Chen XG, Lun ZR. Human angiostrongyliasis. Lancet Infect Dis 2008;8:621-630.

2. Sawanyawisuth $\mathrm{K}$, Chotmongkol V. Eosinophilic meningitis. Handb Clin Neurol 2013;114:207-215.

3. Bunnag T, Benjapong W, Noeypatimanond S, Punyagupta S. The recovery of angiostrongylus cantonensis in the cerebrospinal fluid of a case of eosinophilic meningitis. J Med Assoc Thai 1969;52:665-672.
}

Laopornpichayanuwat S. Angiostrongylus cantonensis in the cerebrospinal fluid of a female child with eosinophilic meningitis in Thailand. Siriraj Hosp Gaz 2000;52:553-558.

5. Eamsobhana P. Angiostrongyliasis in Thailand: epidemiology and laboratory investigations. Hawaii J Med Public Health 2013;72(Suppl 2):S28-S32.

6. Senthong V, Chindaprasirt J, Sawanyawisuth K. Differential diagnosis of CNS angiostrongyliasis: a short review. Hawaii J Med Public Health 2013;72(Suppl 2):S52-S54.

${ }^{1}$ Wiwanitkit House, Bangkhae, Bangkok Thailand;

${ }^{2}$ Visiting professor, Hainan Medical University, China; Visiting professor, Faculty of Medicine, University of Nis, Serbia; Adjunct professor, Joseph Ayobabalola University, Nigeria.

Correspondence: Somsri Wiwanitkit; Wiwanitkit House; Bangkhae; Bangkok Thailand; E-mail: somsriwiwan@hotmail.com

Conflict of interest: There is no conflict of interest to declare.

Received 15 November 2013; Accepted 22 November 2013. 